\title{
Rett Syndrome: Treatment with IGF-1, Melatonin, 3 Blackcurrant Extracts, and Rehabilitation
}

4 Jesús Devesa ${ }^{1, *}$, Olga Devesa 2, María Carrillo ${ }^{2}$, Nerea Casteleiro ${ }^{3}$, Ana Devesa ${ }^{4}$, David Llorente ${ }^{4}$, and Cristina González ${ }^{5}$

1 Scientific Direction. Medical Center Foltra. 15886-Teo. Spain; jesus.devesa@usc.es

2 Speech Therapy. Medical Center Foltra. 15886-Teo. Spain; logopedia@foltra.org

3 Psychomotricity. Medical Center Foltra. 15886-Teo. Spain; neuropsicologia@foltra.org

4 EINA. Medical Center Foltra. 15886-Teo. Spain; estimulacionauditiva@foltra.org

5 Physiotherapy. Medical Center Foltra. 15886-Teo. Spain; fisioterapia@foltra.org

* Correspondence: jesus.devesa@usc.es; Tel.: +34-981-802-128

Abstract: 1) This study describes the good evolution of a 6-year-old girl genetically diagnosed with Rett syndrome (RTT), after having been treated with IGF-1, MT (MT), blackcurrant extracts (BC), and rehabilitation during 6 months. 2) The patient stopped her normal development from the first year of age. The patient showed low weight and height and met the main criteria for typical RTT. Curiously, there was pubic hair (Tanner II), very high plasma testosterone, despite low gonadotropins. No adrenal enzymatic deficits existed, and ultrasound abdominal studies were normal. Treatment consisted in IGF-1 $(0.04 \mathrm{mg} / \mathrm{kg} /$ day, 5/week, sc) during 3-months and then 15-days resting, MT (50 mg/day, orally, uninterruptedly) and neurorehabilitation. The new blood tests were absolutely normal and the pubic hair disappeared. Then, a new treatment with IGF-1, MT, and BC started for another 3 months. After it, pubic Tanner stage increased to III, without a known cause. 3) The treatment followed led to clear improvements in most of the initial impairments, perhaps because of the effect of IGF-I, the antioxidant effects of MT and BC, and the increase in cyclic-glycine-proline (cGP) after BC administration. 4) A continuous treatment with IGF-1, MT and BC may recover most of the neurologic disabilities that occur in RTT.

Keywords: IGF-1; MT; Blackcurrant extracts; Oxidative stress; Mecp2; Speech therapy; Neurostimulation; cyclic glycine-proline; GPE.

\section{Introduction}

Rett syndrome (RTT) was first described by the Austrian doctor Andreas Rett, who gave his name to this serious neurological affectation [1], whose main clinical characteristics were later described in 1983 [2]. In 1999 RTT was postulated to be produced by a de novo mutation in the MECP2 gene, a X-linked gene, that encodes methyl-CpG-binding protein 2 [3]. This protein belongs to a family of proteins [4-5], who play an important role in the organization of chromatin and the regulation of transcription after binding to methylated CpG sites [6], although Mecp2 can also bind to methylated CpA [7]. In fact, methylation of DNA can affect the structure of chromatin and lead to repression of transcription of several different genes. Therefore, mutations in the MECP2 gene, or its deletion, impedes its physiological function as a transcriptional repressor playing a key role in the maturation of the central nervous system (CNS). Most likely, this is the reason by which Mecp2 is mainly present in postmitotic neurons, participating in the development and maintenance of synapses [8], although this protein has been found widely expressed (at different rates depending on the tissue) in most of human adult tissues [9].

Human neural development begins early in the sixth week after conception, a time in which Mecp2 is expressed at low levels [9]. The progression towards an adult brain implies a cascade of expression and sequential repression, critical and closely regulated, of many different genes that 
lead to the formation of different types of neural cells and neuronal connections, migration, and differentiation of neurons, and selective and competitive death of neurons; that favors that only specific and the most important neurons survive. All this is regulated by multiple signals and, as is logical, any alteration in the signaling sequence, produced by genetic anomalies or acquired by external factors dependent on the mother or the external environment (viruses, traumas, etc.) will condition the normal development of the brain. Another very important factor is the mechanism of synapse elimination, something physiologically occurring between early childhood and the beginning of puberty [10]; this phenomenon, known as synaptic pruning, is also influenced by environmental factors.

Although it is not the objective of this study to analyze how normal brain development occurs, this small introduction allows us to understand how the mutation of a gene, such as MECP2, involved in the maturation of the CNS, can produce very important neurological disorders, that in the case of RTT mainly consists of: partial or complete loss of acquired purposeful hand skills; partial or complete loss of acquired spoken language; gait abnormalities; stereotypic hand movements (clapping/tapping). These are the revised diagnostic criteria for RTT, established by RettSearch Consortium in 2010 [11]. In addition, the same RettSearch Consortium established supportive criteria for atypical RTT: breathing disturbances when awake; bruxism when awake; impaired sleep pattern; abnormal muscle tone; peripheral vasomotor disturbances; scoliosis/kyphosis; growth retardation; small cold hands and feet; inappropriate laughing/screaming spells; diminished response to pain; intense eye communication [11].

Until now, there are no specific treatments that could lead to a normalization of the clinical picture of RTT. However, it has been postulated that neurotrophic factors, as IGF-1, that play a key role in the development of the CNS, might improve the symptoms of the syndrome by promoting brain development [12-13], and increasing the low number of dendrites existing in the disease.

In this study, we analyze the evolution of a young girl with RTT, during a 6-months treatment with insulin-like-growth factor 1 (IGF-1), MT, blackcurrant extracts (given during 3-months), and rehabilitation. Although we did not achieve a complete regression of the symptoms observed upon admission, some of them disappeared or clearly decreased along the treatment carried out.

\section{Case Presentation Section}

\subsection{Medical History}

The patient was a 6-year-old, female, genetically diagnosed of Rett syndrome, who came from Bulgaria to the Foltra Medical Center to receive medical treatment. She was the second daughter of three in the family, being her sisters fully normal. There were no problems during pregnancy. Her mother did not have any toxic habit. According to the reports provided by the parents, the delivery took place by cesarean section carried out at week 38 , due to previous cesarean section. Weight at birth was $2.700 \mathrm{~kg}$, her size was $45 \mathrm{~cm}$ and the head circumference was $34.5 \mathrm{~cm}$. In the family there was no medical history of interest. The development of the girl was normal during the first year of life, moment in which she began to present persistent vomiting during 6 months. This led to a series of medical studies until, through genetic tests carried out in the United Kingdom, it was diagnosed that she had Rett syndrome. The girl did not receive any kind of medical treatment. She had two sessions of physiotherapy per week, as well as equinotherapy and music therapy (one session per week in each case).

Upon admission to the Foltra Medical Centre (age 6 years), the patient had a height slightly below $\mathrm{p} 3$ for her age, and her body weight was also below this percentile 3 . She had microcephaly; she walked alone, without any help, but without defined objectives and presenting an increase in the base of support (ataxic ambulation), with short steps. At no time did she interact with who was examining her; continuously she rubbed her hands, she did not attend orders. Nothing caught her attention. There was a convergent strabismus of the left eye. She did not speak. The joint range was 
normal in all 4 limbs, but there was kyphosis and the right scapula was higher than the left. She had drooling. She did not chew and only ate semi-solid foods. She had difficulty drinking. She did not pay attention to anything, she did not pick up objects from the ground, nor did she look into the eyes of the person speaking to her. She often tightly pressed her lips and stopped breathing. There was no sphincter control. The electrocardiogram was normal (frequency: 93 beats per minute). She had never had seizures; however, according to the parents, it was common to wake up 2-3 times during the night. There was a continuous bruxism, day and night.

During the physical examination, the existence of an incipient pubic hair, Tanner II (despite her age), attracted attention, although without a breast button or incipient hair in the armpits. In addition, there was also a discrete clitoromegaly. For these reasons, in addition to the routine blood tests that we requested before starting any medical treatment, in this case the plasma levels of gonadotrophins and sexual hormones were also assessed.

\subsection{Blood analysis}

Upon admission, a blood test was performed. Notably, the number of erythrocytes $(5.37 \mathrm{x}$ $106 / \mu \mathrm{l})$, hemoglobin $(14.40 \mathrm{~g} / \mathrm{dl})$ and hematocrit $(42.2 \%)$ were at high levels, while leukocytes and platelets were in normal values. Plasma biochemistry was normal, excepting creatine phosphokinase (CPK: $315.2 \mathrm{U} / \mathrm{L}$; normal values: 20 - $195 \mathrm{U} / \mathrm{L}$ ). Thyroid hormones were in normal values, as it was plasma cortisol. Plasma IGF-1 and IGFBP3 values were also normal (IGF-I: $68 \mathrm{ng} / \mathrm{ml}$; normal for her age: 55-248 ng/ml. IGFBP3: $4.8 \mathrm{ng} / \mathrm{ml}$; normal for her age: $2.6-5.8 \mathrm{ng} / \mathrm{ml}$ ). Surprisingly, and although the plasma levels of FSH and LH were clearly prepubertal (FSH: $0.80 \mathrm{mU} / \mathrm{ml} ; \mathrm{LH}:<0.1 \mathrm{mU} / \mathrm{ml}$ ), the plasma levels of testosterone were really high $(3.98 \mathrm{ng} / \mathrm{ml}$; normal values in women: $<0.45 \mathrm{ng} / \mathrm{ml})$, equivalent to those of a postpubertal male. Plasma estradiol was lower than $5 \mathrm{pg} / \mathrm{ml}$ (lower limit of the assay).

To rule out a possible deficit of 3 $\beta$-hydroxysteroid dehydrogenase or 21-hydroxylase, despite normal levels of plasma cortisol, a new blood test was performed. However, all steroids measured (dehydroepiandrosterone, dehydroepiandrosterone sulphate and androstenedione) were in normal values for the age of the patient. Therefore, we decided to perform an abdominal ultrasound study that ruled out any anomaly; specifically, the existence of any tumor mass was not detected, the ovaries were normal for age and in them there was no follicular activity.

Based on all this, we suspect that the anomalies detected (pubic hair, clitoromegaly and very high levels of testosterone in plasma) could be related to the previous sustained intake of a food containing androgens.

The blood test was repeated every 3-months until discharge, seven months after admission. Interestingly, 3 months after having started with the medical and rehabilitation treatment, the patient performed a blood test in Bulgaria, her country of origin, to which she had returned during the Christmas holidays. The results of this analysis coincided fully with those that had been made in our center a few days before those holidays. Plasma FSH had increased to $3.30 \mathrm{mU} / \mathrm{ml}$, plasma LH was $0.10 \mathrm{mU} / \mathrm{ml}$, and plasma testosterone was in almost undetectable values $<0.025 \mathrm{ng} / \mathrm{ml}$. Moreover, the pubic hair had practically disappeared (Tanner stage I). This supported our idea of androgen contamination in her food; however, 3-months later, just before discharge, the situation had changed again: the pubic hair was now very black and dense (Tanner stage III, only in the pubic area), and odorous sweating existed. Plasma testosterone was 3,2 ng/ml, and FSH was 4,1 mU/ml, while plasma LH was $1,1 \mathrm{mU} / \mathrm{ml}$. Erythrocytes, hemoglobin and hematocrit also had increased until reaching values similar to those at admission. Plasma IGF-1 was $185 \mathrm{ng} / \mathrm{ml}$, plasma IGFBP3 was 2,7 $\mathrm{ng} / \mathrm{ml}$, and CPK had been normalized (195 U/L). Other plasma values were normal. 


\subsection{Medical treatments}

Once it was established that the testosterone values and pubertal development were not due to an ovarian or adrenal pathology, or to the existence of a tumor process, the medical treatment consisted in the administration of IGF-1 (Increlex, Ipsen Pharma, Barcelona, Spain; 0.04 mg/kg/day, 5 days/week, sc) during 3-months, 15-days resting and again the same dose during other 3-months; Melatonin (MT), $50 \mathrm{mg} /$ day, prepared by master formula and given orally, uninterruptedly, before going to bed. In this second stage of treatment, Currantex 35M (freeze dried blackcurrant extract powder, obtained from the fresh fruit of the Ribes Nigrum L.) was also given orally. These extracts had been prepared as pills by New Zealand Pharmaceuticals NZP (Auckland, New Zealand), each containing 35\% Anthocyanins (35 g/100 g; 43\% Delphinidim-3-rutinoside, $11 \%$ Delphinidin-3-glucoside, 41\% Cyanidin-3-rutinoside, 5\% Cyanidin-3-glucoside). The administered dose consisted of 3 pills daily for three days, then 2 pills daily for three days, and then one daily uninterruptedly.

This medical treatment was conducted in accordance with the protocols followed in our Medical Centre and in compliance with the Spanish legislation for using GH and MT "off label" and the Code of Ethics of the World Medical Association (Declaration of Helsinki). Signed informed consent for using GH and MT, and then Currantex 35M, was obtained from the father of the patient (her legal representative). In the figures shown here, the face of the patient has been partially blurred to preserve her privacy.

No secondary adverse effects due to the medical treatments followed was observed. At discharge, both the height and the weight of the patient had increased, reaching the 5th percentile (p5).

\subsection{Rehabilitation and Results}

Rehabilitation consisted in daily sessions (5 days/week) of Speech Therapy, Neurostimulation and Occupational Therapy, Integrative and Neurosensorial stimulation (EINA), and Physiotherapy (3 days/week).

\section{Speech Therapy}

Initially, the patient presented a severe affectation of expressive and receptive language. She did not understand orders and she did not answer when she was called by her name. She emitted primary sounds to express her mood. She did not chew or crush food, which had to be semi-solid. The swallowing of liquids had to be always using a bottle and in supine position, and the drinks had to be warm or hot. There was a rejection of a series of textures, flavors and temperatures. There was moderate drooling.

The main objective in this area was focused on restoring affected stomatognathic functions through passive rehabilitation techniques focused on myofunctional therapy, improving the swallowing of solids and liquids and acquiring linguistic precursors.

At discharge, the rejection of a series of solid textures had diminished, the voluntary chewing movement had begun, the labial seal had improved (so there was no more drooling); she swallowed liquids at any temperature with a syringe or spoon and had increased the number of babbling and guttural sounds. She even imitated the repetition, in time and type, of certain sounds when she was asked to do it (for instance: O-O-O-O ...... O-O-O-O; U-U-U....U-U-U). The bruxism had disappeared.

These changes are shown in Table 1 and Figure 1. 
187

\begin{tabular}{cc}
\hline Admission & Discharge \\
\hline 3 & 1 \\
\hline
\end{tabular}

188

189

190
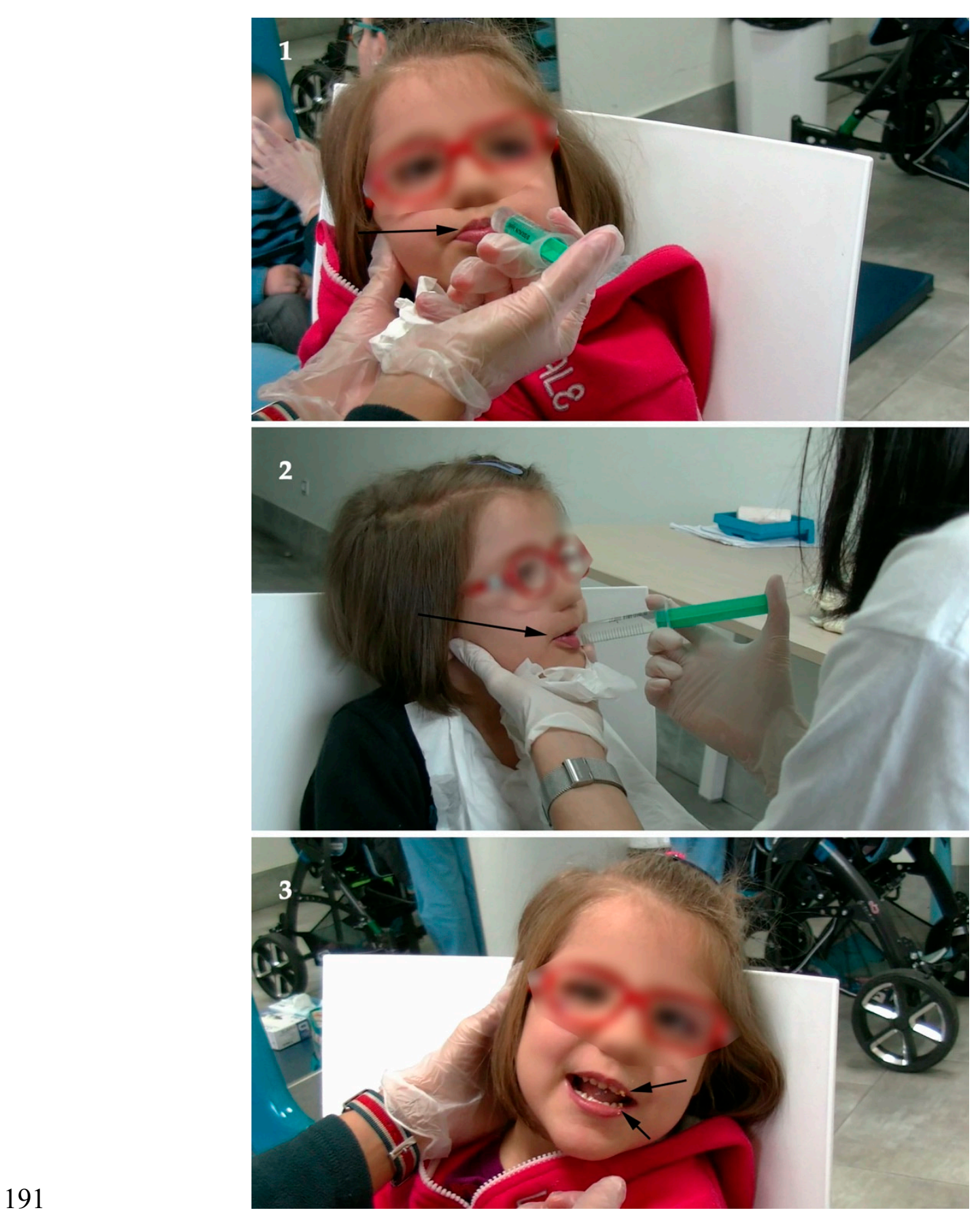

Table 1. Thomas Stonell and Greenberg scale. Upon admission the patient presented a moderate drooling (score 3: wet lips and chin). This score was reduced until 1 at discharge (the patient never drools).

Figure 1. Speech Therapy. 1. Upon admission. Note (black arrow) how the patient seals her lips to prevent the administration of liquids with syringe. 2 and 3. Before discharge. In 2 it can be seen how the patient already accepted to drink with a syringe (black arrow). In 3 small pieces of biscuit can be seen in the mouth (black arrows) after ingesting it. Images have been blurred for avoid the identification of the patient. 


\section{Neurostimulation and Occupational Therapy}

The first exam of the patient showed that there was a marked alteration of the attentional capacity, there was no ocular contact or horizontal or vertical monitoring of the light. She did not interact with other children or adults, she did not recognize herself as a causal agent of events; she did not manipulate objects nor did she have acquired the permanence of them.

Therefore, the objectives in this area were directed to: foster attention, encourage communicative intentionality, explore both different objects and the environment and encourage recognition as the causal agent of events.

At discharge, in the personal and social area the patient had improved the interaction with the adult, being able to look at the face of the subject for marked periods of time and, in many cases, smiled or tried to vocalize as answers. Sometimes she was also able to react in advance to some activities she had been doing during the time of the treatment. The patient had begun to show greater awareness of her hands, using them as support when unbalanced and responding to her name when she was called. She increased his attentional capacity, observed objects and was able to follow a light in both horizontal and vertical paths for longer periods of time. In relation to fine motor skills she now keeps her hands predominantly open and began to perform ulna-palmar pressure, as well as began to touch and explore objects. As for receptive communication, she began to react to sounds that were outside her field of vision by turning her head towards the source and reacting to different types of voice. At the cognitive level, her mnesic capacity increased, as did the perceptive discrimination, reacting to new situations and beginning to visually explore her environment.

These changes are shown in Table 2 and Figure 2.

\begin{tabular}{|c|c|c|}
\hline AREA & PRE- & POST- \\
\hline Social/Personnel & 0 & 2 \\
\hline Adaptive & 1 & 3 \\
\hline Gross motor & 6 & 2 \\
\hline Fine motor & 0 & 6 \\
\hline TOTAL MOTOR & 3 & 5 \\
\hline Receptive communication & 1 & 2 \\
\hline Expressive communication & 1 & 3 \\
\hline TOTAL COMMUNICATION & 1 & 4 \\
\hline Cognition & 1 & 3 \\
\hline TOTAL & 2 & \\
\hline
\end{tabular}

Table 2. Scores reached in the Battelle Developmental Inventory Screening Test (BDIST) at admission (PRE-) and at discharge (POST-). Mainly note the changes observed in adaptive behavior, receptive communication and cognition. 

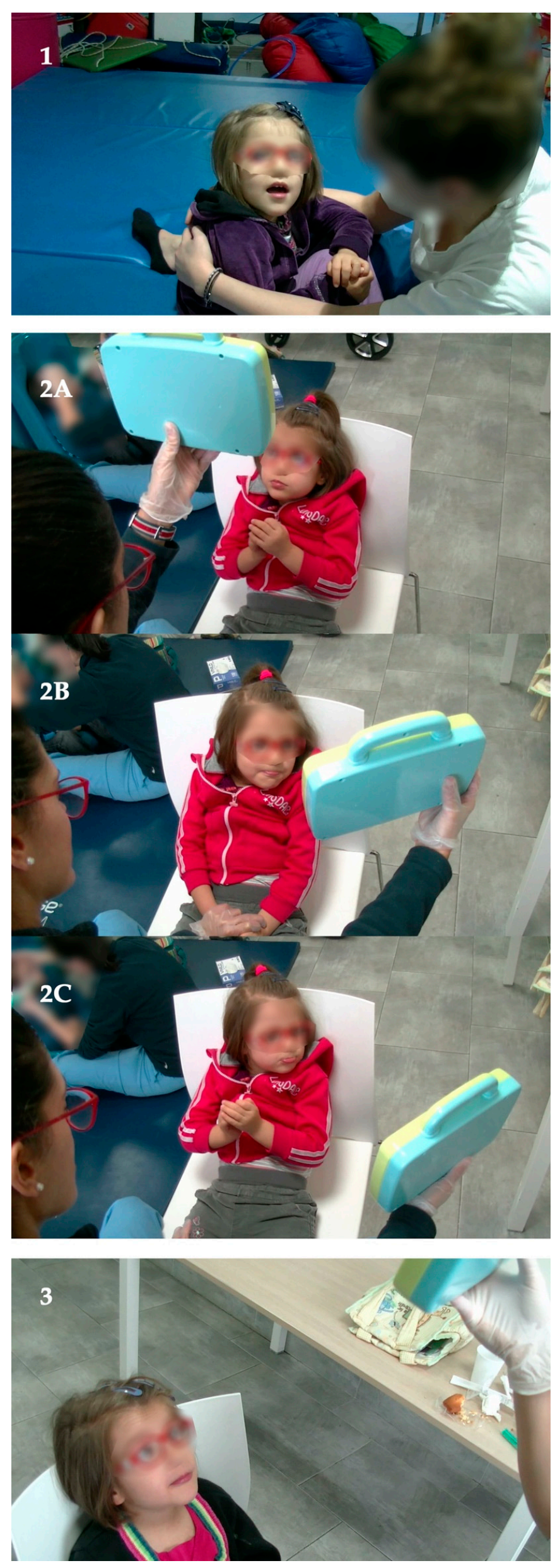
Figure 2. Interaction with objects. 1. At admission, the patient did not look at the face of the therapist or to any other person. 2 (A to $\mathrm{C}$ ) and 3. Before discharge she was following objects; these images show how the patient was following cartoons shown on a tablet.

\section{EINA}

The objective of this therapy was to stimulate the brain through the ear [14], seeking a motor and cognitive improvement and improving the results of other therapies performed by the patient.

In this case, given the condition and the lack of speech of the patient the initial and final listening tests could not be performed. Therefore, the changes that could have occurred could not be evaluated graphically. In any case, four different blocks of stimulation were carried out, with a week of interval between them. In the first two blocks, the patient listened to filtered Mozart music, Gregorian chants, and passing bands. During the third block, only Mozart music and Gregorian chants were used for brain stimulation, whereas in the fourth block the stimulation was carried out with passing bands related to balance and coordination; for this, the sound was filtered, enhancing the frequencies between 125 and $1000 \mathrm{~Hz}$, so that the stimulation took place at the vestibular level.

\section{Physiotherapy}

At the beginning of these sessions the patient did not make postural changes. When sitting on a chair, she remained passively in it. When she was placed on the floor, she did not move or try to get up. Her defense reactions were poor, as were her straightening responses. She did not crawl, or go down or up the stairs. When she walked, she did so by increasing the base of support.

Before discharge most of these impairments had disappeared. The patient was now able to move from the supine to the prone position and vice versa. In the supine position she pushed himself to sit down; she was able to go up and down stairs and she walked with more balance, without needing to increase the base of support. Also, seeing her therapist, her face showed an expression of joy and approached her. Some of these changes are shown in Figure 3.

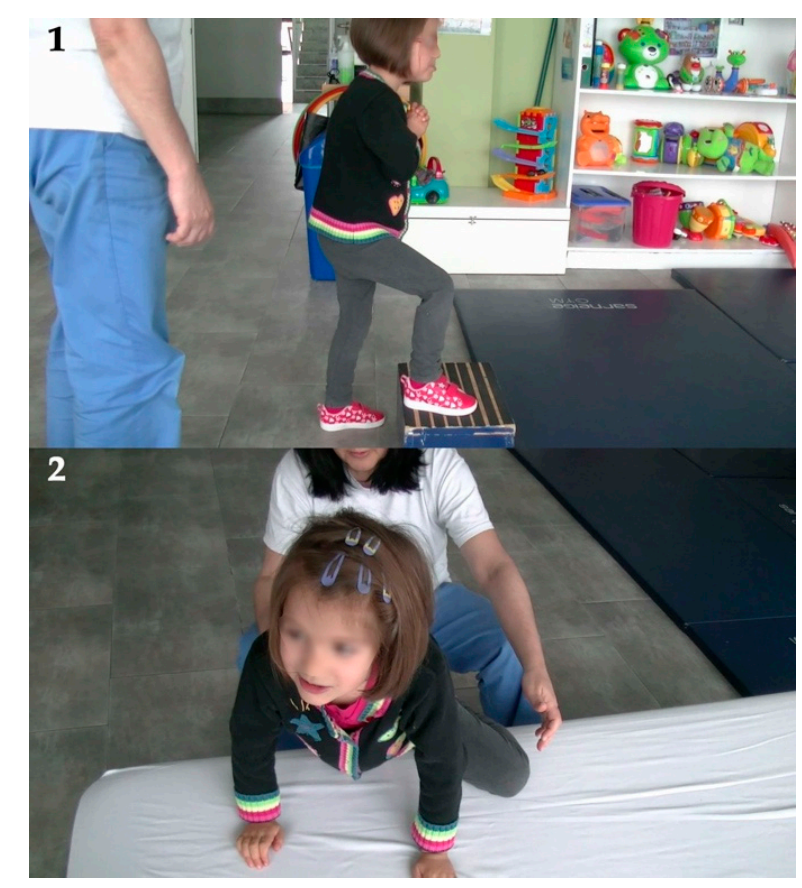


254 Figure 3. Increased motor abilities observed at discharge. 1. The patient is now able to climb stairs. 2. The

255 patient is able to get on a bed with the help of her hands.

\section{3. Discussion}

This study analyzes the evolution of a six years old girl that fulfilled the main criteria required 258 for typical Rett syndrome diagnosis, established in 2010 by the RettSearch Consortium [11]. 259 Moreover, the patient also showed many of the supportive criteria also established by this group 260 [11], and had a genetic confirmation of the existence of a mutation in the MECP2 gene, responsible 261 for the development of this syndrome, present in 1:10,000 females and the second known cause of important intellectual disabilities in them. We treated her with IGF-1, MT, blackcurrant extracts and rehabilitation during a short period of time (six months of treatment with IGF-1 and MT, and then blackcurrant extracts were also added), and the results obtained have to be considered as good in terms of some improvements in her disabilities.

As stated in the Introduction, Mecp2 plays a key role in the development of the brain, mainly acting on the formation of synaptic connections. Therefore, any mutation in the gene encoding the expression of this protein has to be expected to produce devastating disorders, due to the lack of synapses and their dysfunction, as it occurs in RTT [15]. Studies in mice have shown that these deficits can be recovered, at least partially, if there is a postnatal activation of Mecp2 [16, 17]. This has been shown to occur with the administration of IGF-1, who recovers dendritic spines in mice deficient in Mecp2, although this treatment has to begin very early, when the phenotype of the syndrome is still not too severe [18]. The positive effects of IGF-1 administration in RTT have been confirmed in mouse models [19, 20], and in human patients [12, 13, 21-23], corroborating our results in this study.

Many reasons can explain why IGF-1 exerts positive effects on RTT. In rats, IGF-1 is widely expressed in many brain areas, although its expression soon decreases after birth [24], most likely in a way similar to what happens in humans; in fact, IGF-1 expression has been found in neural stem cells derived from fetal human forebrains [25]. In contrast, the receptor of IGF-1 (IGF-1R) maintains a stable expression in the brain throughout life [26], perhaps to bind to the IGF-I that, coming from the plasma, reaches the brain crossing the blood-brain barrier [27]. The binding of IGF-1 to its receptor, a membrane-bound tyrosine kinase, induces the activation of the PI3K/Akt and MAPK (Mitogen-Activated Protein Kinases, also known as ERK: Extracellular signal-regulated kinases) signaling pathways, who are also transduction pathways of BDNF (Brain Derived Nerve Factor) [28], a peptide with important neurotrophic activities, among them inducing synaptic plasticity, which, interestingly, is transcriptionally regulated by Mecp2 [29]. This explains why MECP2 gene deficiencies or mutations lead to a marked downregulation of BDNF expression in the brain of RTT mice or humans [30, 31], but also why IGF-1 administration may contribute to improve some of the neurological abnormalities observed in RTT. Moreover, plasma levels of IGF-1 levels have been found to be decreased in 8 of 23 RTT patients [32], and the GH/IGF-1 axis has been shown to function abnormally in RTT [33]. However, treating RTT patients with IGF-1 implies its administration during the whole life, which is risky because of its mitogenic potential.

In 1989 it was identified that in the brain, IGF-1 suffered a specific proteolytic cleavage leading to the generation of two fragments: des-N-(1-3)-IGF-1, and the N-terminal tripeptide Gly-Pro-Glu (GPE) [34]. This mechanism of breakage of IGF-1 was further identified in the serum of the rat [35], and GPE was also detected in human urine [36]. Soon it was discovered that this peptide was not only a mere product of degradation of IGF-1, but it exerted important activities at brain level (see [37] for review), acting as neuromodulator, neuroprotector and even inducing the proliferation and migration of neural stem cells [37]. In addition, our data demonstrated that GPE signals through activation of the PI3K/Akt and MAPK (ERK) pathways, as do IGF-1 and BDNF [37]. However, the short life of GPE in plasma when administered intravenously limits its therapeutic use. Currently, a chemically modified form of GPE, called Trofinetide (formerly called NNZ-2566), makes the peptide suitable for oral administration, with a longer half-life in plasma and easy passage to the brain. 
These are the reasons by which this modified GPE is being used in clinical trials in RTT human patients with significantly promising results.

Another metabolite of IGF-1, possibly derived from GPE, is the dipeptide cyclic-glycine-proline (cGP). This small peptide has been shown to act by modulating the bioavailability of IGF-1, that is the amount of free IGF-1, the biologically active fraction. cGP regulates the binding of IGF-1 to its binding proteins, particularly to IGFBP3, therefore normalizing IGF-1 function under pathological conditions [38, 39]. In this sense, it has been shown that cGP increases the activity of IGF-1 when it is low (as occurs in the RTT brain), but inhibits it when IGF-1 is in high values; this may explain why IGF-1 can show effects as different as improving the recovery of brain lesions in rats and decreasing or inhibiting the growth of some tumors in mice [38], but also why cGP improves memory in adult rats [40].

On the other hand, it has been demonstrated that oxidative stress (OS) exists in RTT patients [41], although there are doubts about whether this increase in OS occurs due to the disease or is the factor responsible for it [42]. Animal studies showed a clear increase in the production of harmful reactive oxygen species in the brain of mice deficient in $\mathrm{MeCP} 2$, apparently produced by a defective functioning of complex II of the mitochondrial respiratory chain, that could be recovered with the administration of a bacterial protein, CNF1, which had also been shown to improve the affected neural phenotype of these animals [43]. Even though it has been suggested that RTT could be a mitochondrial disease, the discovery of mutations of the MECP2 gene showed that they precede mitochondrial dysfunction [44], although it is clear that OS plays a very important role in expression and severity of the symptoms in the disease; therefore, treating mitochondrial dysfunction or the use of reactive oxygen species scavengers may be useful in RTT patients [44].

This was one of the reasons why we used MT in our patient. Seminal studies demonstrated that MT exerts potent scavenging effects on toxic reactive oxygen species [45, 46]; in addition, this hormone has anti-inflammatory properties and is a mitochondrial protector, besides playing many other important roles in the body [47-50]. In RTT, as in many other central nervous system pathologies, neuroinflammation is the most frequent finding. It mainly occurs as a result of overproduction of inflammatory cytokines leading to an increased stress on brain cells and a strong activation of microglia. Microglia plays a prominent role in maintaining synapsis and pruning dendrites, but these abilities are lost when it is over-activated. Therefore, the administration of MT must have played an important role in the positive evolution of our patient RTT, added to the administration of IGF-1 (which, as previously indicated, is deficient in the brain of RTT).

Interestingly, the positive evolution of the patient was even greater when we were able to give her blackcurrant extracts in addition to IGF-1 and MT. It is not the objective of this study to analyze the properties of these anthocyanins, but studies carried out years ago show that they act as strong antioxidants, anti-inflammatories and anti-neurodegeneration. Of interest here is that the extracts we have used have recently been described that act through the mitochondrial pathways PI3k/Akt and MAPK, at least in cancer cell line cultures [51]. In addition, it has been demonstrated that the administration of 28 days of black currant anthocyanin increased the concentration of cGP in cerebrospinal fluid samples collected from 11 patients with Parkinson's disease; this increase in cerebral cGP correlated with plasma cGP concentration and plasma cGP / IGF-1 ratio, without modifying the concentration of IGF-1 and IGFBPs in both plasma and cerebrospinal fluid [52]. Therefore, it is likely that the blackcurrant extracts contributed significantly, acting as antioxidants, anti-inflammatory and increasing the bioavailability of cerebral IGF-1 (free IGF-1), to the additional positive evolution of our patient with RTT.

At this point, it seems to be possible to explain the unexpected and discrepant findings observed in the gonadotropic axis and pubertal development of the patient throughout the treatment, a finding not described before.

Although we did not evaluate the secretion of growth hormone (GH), presumably this was elevated, despite her low height, before commencing the treatment with IGF-1 and MT. Plasma IGF-1 values were low and this leads to increased GH release [53]. GH exerts an important stimulatory role on the gonads [54]; it is, therefore, possible that a high secretion of GH has 
contributed to the high levels of testosterone initially observed and the incipient pubertal development, despite the low levels of FSH and LH. When the treatment began and IGF-1 was given, plasma IGF-1 values increased leading to diminished GH secretion. When the patient started treatment and IGF-1 was administered, the plasma IGF-1 values increased, which had to lead to a decrease in GH secretion. This may explain why pubic hair disappeared and plasma testosterone levels were undetectable in the next two analysis carried out. However, shortly after the administration of blackcurrant extracts, pubertal development reappeared and with greater intensity. This may depend on increased IGF-1 bioavailability, due to increased plasma cGP [52]; IGF-1 seems to act synergistically with GH, or independently of it in gonadal functions [53]. This explanation is merely speculative, but it merits further studies.

In summary, treatments with IGF-1, MT and blackcurrant extracts are useful for improving the neurologic disabilities existing in girls with Rett syndrome. Since extracts of blackcurrant increase the levels of cGP, the mitogenic potential of IGF-1 can be counteracted, so that treatments with this hormone can be prolonged longer. There is the need to investigate whether the androgenic abnormalities observed in our patient and their changes could have been produced by any of the treatments given.

A limitation of this study is the fact that the girl was used to listen Bulgarian language, very different from the Spanish used by her therapists, as well as the fact that she could only receive treatment for six months due to the work of her parents in their country. Currently, she is still treated with MT and blackcurrant extracts there, but without IGF-1, waiting for the European approval of GPE.

Author Contributions: For research articles with several authors, a short paragraph specifying their individual contributions must be provided. The following statements should be used "Conceptualization, J.D.; Methodology, O.D., M.C., N.C., A.D., D.L., C.G. and J.D; Validation, J.D.; Formal Analysis, O.D., M.C., N.C., A.D., D.L., C.G. and J.D.; Investigation, J.D.; Writing-Review \& Editing, J.D.; Supervision, J.D.;

Funding: "This research received no external funding”.

Acknowledgments: We acknowledge Mr. David Eder (VitalityNZ, New Zealand) for his generous gift of Currantex 35M. We also acknowledge Dr. Jian Guan (Liggins Institute, Auckland, New Zealand) for her advices and explanations about cGP--IGF-1 relationships and effects on the central nervous system.

Conflicts of Interest: “The authors declare no conflict of interest."

\section{References}

1. Rett, A. On an unusual brain atropic syndrome with hyperammonemia in childhood. Wien Med Wochenschr 1966, 116, 723-726.

2. Hagberg, B.; Aicardi, J.; Dias, K.; Ramos, O. A progressive syndrome of autism, dementia, ataxia, and loss of purposeful hand use in girls: Rett's syndrome: report of 35 cases. Ann Neurol 1983, 14, 471-9.

3. Amir, R.E.; Van den Veyver, I.B.; Wan, M.; Tran, C.Q.; Francke, U.; Zoghbi, H.Y. Rett syndrome is caused by mutations in X-linked MECP2, encoding methyl-CpG-binding protein 2. Nat Genet 1999, 23, 185-8.

4. Lewis, J.D.; Meehan, R.R.; Henzel, W.J.; Maurer-Fogy, I.; Jeppesen, P.; Klein, F. et al. Purification, sequence, and cellular localization of a novel chromosomal protein that binds to methylated DNA. Cell 1992, 69, 905-14.

5. D'Esposito, M.; Quaderi, N.A.; Ciccodicola, A.; Bruni, P.; Esposito, T.; D'Urso, M. et al. Isolation, physical mapping, and northern analysis of the X-linked human gene encoding methyl CpG-binding protein, MECP2. Mamm Genome 1996, 7, 533-5.

6. Galvão, T.C.; Thomas, J.O. Structure-specific binding of MeCP2 to four-way junction DNA through its methyl CpG-binding domain. Nucleic Acids Res 2005, 33, 6603-9.

7. Guo, J.U.; Su, Y.; Shin, J.H.; Shin, J.; Li, H.; Xie, B. et al. Distribution, recognition and regulation of non-CpG methylation in the adult mammalian brain. Nat Neurosci 2014, 17, 215-22. 
8. Shahbazian, M.D.; Antalffy, B.; Armstrong, D.L.; Zoghbi, H.Y. Insight into Rett syndrome: MeCP2 levels display tissue- and cell-specific differences and correlate with neuronal maturation. Human Mol Genet 2002, 11, 115-24.

9. Meehan, R.R.; Lewis, J.D.; Bird, A.P. Characterization of MeCP2, a vertebrate DNA binding protein with affinity for methylated DNA. Nucleic Acids Res 1992, 20, 5085-92.

10. Chechnik, G.; Meilijson, I.; Ruppin, E. Synaptic pruning in development: a computational account. Neural computation 1998, 10, 1759-77.

11. Neul, J.L.; Kaufmann, W.E.; Glaze, D.G. Christodolou, J.; Clarke, A.J.; Bahi-Buisson, N. et al. Rett Syndrome: Revised Diagnostic Criteria and Nomenclature. Ann Neurol 2010, 68, 944-50.

12. Pini, G.; Scusa, M.F.; Congiu, L.; Benincassa, A.; Morescalchi, P.; Bottiglioni, I. et al. IGF1 as a Potential Treatment for Rett Syndrome: Safety Assessment in Six Rett Patients. Autism Res Treat 2012, 2012, 679801.

13. Pini, G.; Scusa, M.F.; Benincassa, A.; Bottiglioni, I.; Congiu, L.; Vadhatpour, C.et al. Repeated insulin-like growth factor 1 treatment in a patient with Rett syndrome: a single case study. Front Pediatr 2014, $2,52$.

14. Quintana, A.; Agra, C.; Outeiral, L.; Devesa, A.; Llorente, D.; Devesa, J. Cognitive evolution of a patient who suffered a Subarachnoid Haemorrhage eight years ago, after being treated with Growth Hormone, MT and Neurorehabilitation. Reports 2018, 1, 2.

15. Kaufmann, W.E.; Johnston, M.V.; Blue, M.E. MeCP2 expression and function during brain development: implications for Rett syndrome's pathogenesis and clinical evolution. Brain Dev 2005, 27 (Suppl 1), S77-87.

16. Giacometti, E.; Luikenhuis, S.; Beard, C.; Jaenisch, R. Partial rescue of MeCP2 deficiency by postnatal activation of MeCP2. Proc Natl Acad Sci U S A 2007, 104, 1931-6.

17. Guy, J.; Gan, J.; Selfridge, J.; Cobb, S.; Bird, A. Reversal of neurological defects in a mouse model of Rett syndrome. Science 2007, 315, 1143-7.

18. Landi, S.; Putignano, E.; Boggio, E.M.; Giustetto, M.; Pizzorusso, T.; Ratto, G.M. The short-time structural plasticity of dendritic spines is altered in a model of Rett syndrome. Sci Rep 2011, 1, 45.

19. Tropea, D.; Giacometti, E.; Wilson, N.R.; Beard, C.; McCurry, C.; Fu, D.D. et al. Partial reversal of Rett Syndrome-like symptoms in MeCP2 mutant mice. Proc Natl Acad Sci U S A 2009, 106, 2029-2034.

20. Castro, J.; García, R.I.; Kwok, S.; Banerjee, A.; Petravicz, J.; Woodson, J. et al. Functional recovery with recombinant human IGF1 treatment in a mouse model of Rett Syndrome. Proc Natl Acad Sci U S A 2014, 111, 9941-6.

21. Khwaja, O.S.; Ho, E.; Barnes, K.V.; O'Leary, H.M.; Pereira, L.M.; Finkelstein, Y., et al. Safety, pharmacokinetics, and preliminary assessment of efficacy of mecasermin (recombinant human IGF-1) for the treatment of Rett syndrome. Proc Natl Acad Sci U S A 2014, 111, 4596-4601.

22. Pini, G.; Congiu, L.; Benincasa, A.; DiMarco, P.; Bigoni, S.; Dyer, A.H. et al. Illness Severity, Social and Cognitive Analysis, and EEG Analysis of Ten Patients with Rett Syndrome Treated with Mecasermin (Recombinant Human IGF-1). Autism Res Treat 2016, 2016, 5073078.

23. Riikonen, R. Treatment of autistic spectrum disorder with insulin-like growth factors. Eur J Paediatr Neurol 2016, 20, 816-23.

24. García-Segura, L.M.; Pérez, J.; Pons, S.; Rejas, M.; Torres-Alemán, I. Localization of insulin-like growth factor I (IGF-I)-like immunoreactivity in the developing and adult rat brain. Brain Res 1991, 560, 167-74.

25. Pathipati, P.; Gorba, T.; Scheepens, A.; Goffin, V.; Sun, Y.; Fraser, M. Growth hormone and prolactin regulate human neural stem cell regenerative activity. Neuroscience 2011, 190, 409-27.

26. Bondy, C.; Werner, H.; Roberts, C.T. Jr.; LeRoith, D. Cellular pattern of type-I insulin-like growth factor receptor gene expression during maturation of the rat brain: comparison with insulin-like growth factors I and II. Neuroscience 1992, 46, 909-23.

27. Fernández, A.M.; Torres-Alemán, I. The many faces of insulin-like peptide signaling in the brain. Nat Rev Neurosci 2012, 13, 225-39.

28. Duman, R.S.; Voleti, B. Signaling pathways underlying the pathophysiology and treatment of depression: novel mechanisms for rapid-acting agents. Trends Neurosci 2012, 35, 47-56.

29. Xu, X.; Miller, E.C.; Pozzo-Miller, L. Dendritic spine dysgenesis in Rett syndrome. Front Neuroanat 2014, 8, 97.

30. Riikonen, R. Neurotrophic factors in the pathogenesis of Rett syndrome. J Child Neurol 2003, 18, 693-7.

31. Abuhatzira, L.; Makendoski, K.; Kaufman, Y.; Razin, A.; Shemer, R. MeCP2 deficiency in the brain decreases BDNF levels by REST/COREST-mediated repression and increases TRKB production. Epigenetics 2007, 2, 214-22. 
460

461

462

463

464

465

466

467

468

469

470

471

472

473

474

475

476

477

478

479

480

481

482

483

484

485

486

487

488

489

490

491

492

493

494

495

496

497

498

499

500

501

502

503

504

505

506

507

508

509

32. Huppke, P.; Roth, C.; Christen, H.J.; Brockmann, K.; Hanefeld, F. Endocrinological study on growth retardation in Rett syndrome. Acta Paediatr 2001, 90, 1257-61.

33. Hara, M.; Nishi, Y.; Yamashita, Y.; Hirata, R.; Takahashi, S.; Nagamitsu, S. et al. Relation between circulating levels of GH, IGF-1, ghrelin and somatic growth in Rett syndrome. Brain Dev 2014, 36, 794-800.

34. Sara, V.R.; Carlsson-Skwirut, C.; Bergman, T.; Jörnvall, H.; Roberts, P.J.; Crawford, M. et al. Identification of Gly-Pro-Glu (GPE), the aminoterminal tripeptide of insulin-like growth factor 1 which is truncated in brain, as a novel neuroactive peptide. Biochem Biophys Res Commun 1989, 165, 766-71.

35. Yamamoto, H.; Murphy, L.J. Enzymatic conversion of IGF-I to des (1-3) IGF-I in rat serum and tissues: A further potential site of growth hormone regulation of IGF-I action. J Endocrinol 1995, 146, 141-8.

36. Yamamoto, H.; Murphy, L.J. N-terminal truncated insulin-like growth factor-I in human urine. J Clin Endocrinol Metab 1995, 80, 1179-83.

37. Almengló, C.; Devesa, P.; Devesa, J.; Arce, V. GPE promotes the proliferation and migration of mouse embryonic neural stem cells and their progeny in vitro. Int J Mol Sci 2017, 18, 1280.

38. Guan, J.; Gluckman, P.; Yang, P.; Krissansen, G.; Sun, X.; Zhou, Y. et al. Cyclic glycine-proline regulates IGF-1 homeostasis by altering the binding of IGFBP-3 to IGF-1. Sci Rep 2014, 4, 4388.

39. Sing-Mallah, G.; McMahon, C.D.; Guan, J.: Singh, K. Cyclic-glycine-proline accelerates mammary involution by promoting apoptosis and inhibiting IGF-1 function. J Cell Physiol 2017, 232, 3369-83.

40. Singh-Mallah, G.; Sing, K.; McMahon, C.D.; Harris, P.; Brimble, M.A. et al. Maternally administered Cyclic Glycine-Proline increases Insulin-Like Growth Factor-1 Bioavailability and Novelty Recognition in Developing Offspring. Endocrinology 2016, 157, 3130-9.

41. De Felice, C.; Signorini, C.; Leoncini, S.; Pecorelli, A.; Durand, T.; Valacchi, G. et al. [Oxidative stress and Rett syndrome]. Minerva Pediatr 2014, 66, 41-62.

42. Filosa, S.; Pecorelli, A.; D'Esposito, M.; Valacchi, G.; Hajek, J. Exploring the possible link between MeCP2 and oxidative stress in Rett syndrome. Free Radic Biol Med 2015, 88, 81-90.

43. De Filippis, B.; Valenti, D.; de Bari, L.; De Rasmo, D.; Musto, M.; Fabbri, A. et al. Mitochondrial free radical overproduction due to respiratory chain impairment in the brain of a mouse model of Rett syndrome: protective effect of CNF1. Free Radic Biol Med 2015, 83, 167-77.

44. Shulyakova, N.; Andreazza, A.C.; Mills, L.R.; Eubanks, J.H. Mitochondrial dysfunction in the pathogenesis of Rett syndrome: implications for Mitochondria-Targeted Therapies. Front Cell Neurosci 2017, 11, 58.

45. Reiter, R.J. Functional aspects of the pineal hormone MT in combating cell and tissue damage induced by free radicals. Eur J Endocrinol 1996, 134, 412-30.

46. Reiter, R.J. Antioxidant actions of MT. Adv Pharmacol 1997, 38,103-17

47. Sánchez, A.; Calpena, A.C.; Clares, B. Evaluating the Oxidative Stress in Inflammation. Int J Mol Sci 2015, 16, 16981-17004.

48. Dong, Y.; Fan, C.; Hu, W.; Jiang, S.; Ma, Z.; Yan, X. et al. MT attenuated early brain injury induced by subarachnoid hemorrhage via regulating NLRP3 inflammasome and apoptosis signaling. J. Pineal Res 2016; 60:253-262.

49. Carrascal, L.; Nunez-Abades, P.; Ayala, A.; Cano, M. Role of MT in the inflammatory process and its therapeutic potential. Curr Pharm Des 2018, [Epub ahead of print].

50. Cardinali, D.P.; Vigo, D.E. MT, mitochondria, and the metabolic syndrome. Cell Mol Sci 2017, 74, 3941-54.

51. Liu, B.; Li, Z. Black Currant (Ribes nigrum L.) extract induces apoptosis of MKN-45 and TE-1 cells through MAPK- and PI3K/Akt-Mediated Mitochondrial Pathways. J Med Food 2016, 19, 365-73.

52. Guan, J.; Alamri, Y.; Fan, D.; MacAskill, M.; Anderson, T. Cyclic glycine-proline increased in the cerebrospinal fluid of Parkinson's patients after supplementation of blackcurrant anthocyanins: Potential biomarker for treatment [abstract]. Mov Disord 2016, 31 (suppl 2).

53. Devesa, J.; Lima, L.; Tresguerres, J.A. Neuroendocrine control of growth hormone secretion in humans. Trends Endocrinol Metab 1992, 3, 175-83.

54. Devesa, J.; Almengló, C.; Devesa, P. Multiple Effects of Growth hormone in the Body: Is it Really the Hormone for Growth? Clin Med Insights Endocrinol Diabetes 2016, 9, 47-71. 